\title{
Applying biomass dynamic models to the southern horse mackerel stock (Atlantic waters of Iberian Peninsula). A comparison with VPA-based methods*
}

\author{
PABLO ABAUNZA ${ }^{1}$, A. CELSO FARIÑA ${ }^{2}$ and ALBERTO MURTA ${ }^{3}$ \\ ${ }^{1}$ Instituto Español de Oceanografía. Apdo: 240, 39080 Santander, Spain. E-mail: pablo.abaunza@st.ieo.es \\ ${ }^{2}$ Instituto Español de Oceanografía. Apdo: 130, 15080 A Coruña, Spain. \\ ${ }^{3}$ Instituto de Investigação das Pescas e do Mar, Av. Brasilia, 1400 Lisboa, Portugal.
}

\begin{abstract}
SUMMARY: The horse mackerel (Trachurus trachurus) fishery of the Northeast Atlantic, is currently subject to assessment and management in the ICES area. Assessment of the Southern horse mackerel (ICES Divisions VIIIc and IXa) is made with Virtual Population Analysis (VPA), using time series of catch-at-age data and catch-per-unit-of-effort (CPUE) from 1985 to present. The application of biomass-dynamic models to the assessment and catch prediction of this stock has never been attempted before. In this paper, a production model is applied to the Southern horse mackerel stock. To quantify uncertainty in parameter estimates, bootstrap confidence intervals were computed, which showed that estimates could be considered as reliable. The bootstrap standard deviations of $F_{t}, r, M S Y$ and $F_{M S Y}$ were relatively small, despite the lack of trends in the available effort series. On the contrary, the catchability, $q$, showed a coefficient of variation of $74 \%$. The current level of fishing mortality for 1998 was considered as unsustainable for the resource, being well above $F_{M S Y}$ according to the biomassdynamic models, and above $F_{p a}$ according to the age-structured model. Both models were in close agreement on the time series of fishing mortality and in the perception of the state of the stock. Differences existed in the changes in stock biomass especially over the last years. Over this time period the age-structured model showed an increasing trend in biomass. The estimates of $M S Y$ and $F_{M S Y}$ were in accordance with the precautionary approach philosophy. The biomass-dynamic model used here was usefully applied to the Southern horse mackerel stock, giving complementary information to the age-structured model, both in the perception of the state of the stock and in the definition of management targets.
\end{abstract}

Key words: Trachurus trachurus, Biomass-dynamic models, Schaefer, Parameter estimation, Virtual population analysis, Comparison of models, Reference points.

\section{INTRODUCTION}

Almost all fish stocks under management in the ICES area are assessed with age-structured models (Patterson and Kirkwood, 1995; ICES, 1999a). Where no information on age or length structure exists, biomass-dynamic models, or production models, are applied (Chen and Andrew, 1998). In recent years, biomass-dynamic models have been reevaluated, and applied independently of the avail-

\footnotetext{
*Received August 25, 2000. Accepted January 30, 2002.
}

ability of age or length data (Hilborn and Walters, 1992). Some of the supporting arguments are: i) the quality of parameter estimates and management procedures are similar to or better than those generated by age-structured approaches (Ludwig and Walters, 1985; Quinn et al., 1985; Punt, 1995); ii) data requirements are modest and simple, easing exploration of the model properties (Prager, 1994) and iii) high versatility, making these models suitable for fisheries analysis and for management situations with a great stochasticity (Getz and Haight, 1989; Lalöe, 1995). 
The Southern horse mackerel stock, distributed in the Atlantic waters off the Iberian Peninsula, has a well known length and age structure. Since 1985, catch at age data and CPUE at age series are available (ICES, 2000). Since 1992, assessments have been performed annually by applying age-based models (VPA), in particular Extended Survivor Analysis (XSA) (Shepherd, 1999). The results have invariably shown a quasi-equilibrium state, without large changes in fishing mortality or in the spawning stock biomass. The stock could be classified as "harvested stock" or a stock in which the fishing mortality level is slightly over the recommended precautionary approach level but in which the spawning stock biomass is above the level considered as stock potentially depleted or overfished (see ICES, 2000).

There are no previous comparisons of age-structured models and biomass-dynamic models for horse mackerel stocks in the ICES area. For other species, ICES (1999b) reports some trial applications of biomass-dynamic models to several stocks, but with poor results and without any direct comparison with age-based models. References to comparisons are also few for other areas (Ludwig and Walters, 1985; Quinn et al., 1985; Punt, 1995).

In this paper the Schaefer model (Schaefer, 1954) is fitted to a time series of catches and CPUE using an optimisation method, and assuming that errors are present in the CPUE but not in the catches. The following quantities are estimated: the virgin biomass or carrying capacity $K$, the current level of biomass $B$, the intrinsic growth rate $r$, the catchability $q$, the maximum sustainable yield $M S Y$ and the level of fishing mortality at which $M S Y$ is achieved $F_{M S Y}$. These parameters are compared with fishing mortality and stock biomass estimates from XSA and yield per recruit analysis, to see if there is agreement between models regarding the state of the stock.

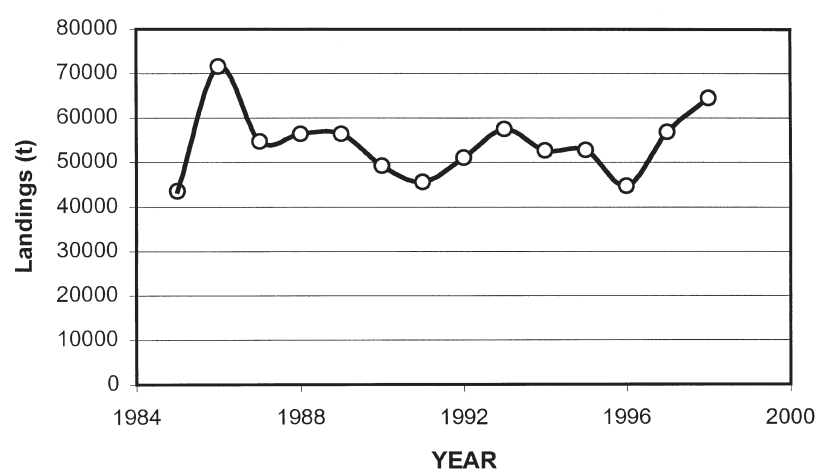

FIG. 1. - Total landings (1985-1998) of Southern horse mackerel stock.
The aim of this paper is to increase the current knowledge on the dynamics of the Southern horse mackerel stock, and to test if biomass-dynamic models are likely to provide better estimates of management parameters than age-based models. The reference points are analysed under the philosophy of the precautionary approach (Caddy and Mahon, 1995).

\section{MATERIAL AND METHODS}

\section{Age-based models}

The data required to run the XSA software (Darby and Flatman, 1994) and considered for the assessment of the Southern horse mackerel stock for the period 1985-1998 are: catch in numbers at age, weight at age in the catch, weight at age in the stock, natural mortality $(M)$ at age, proportion mature at age, proportion of $M$ before spawning, proportion of fishing mortality $(F)$ before spawning, and CPUE at age (from two series of commercial fleets and three series of bottom trawl surveys). Further details of these data are reported in ICES (2000). The XSA calculates fleet (or survey) based estimates of population abundance at age, and then a least squares estimate of the survivors at the end of each year is calculated. These estimates are used to initiate the cohort analysis (Pope, 1972) in an iterative process. For a detailed description of the model and algorithm see Darby and Flatman (1994) and Shepherd (1999).

\section{Biomass-dynamic models}

\section{Fishery information}

Catch data of Southern horse mackerel stock are available from 1985 to 1998 (Fig.1). Catch reports are quite good and misreported catches and discards are negligible (Pérez et al., 1999).

\section{CPUE and effort data}

Five time series of CPUE and effort data are available, two from commercial fleets and three from bottom trawl surveys (Table 1). The two commercial fleets are bottom trawlers that operate in the northern coast of Spain during the whole year. Two series of bottom trawl surveys are carried out in July and in October along the Portuguese continental shelf, and the other series is carried out in October 
TABLE 1. - Southern horse mackerel stock. CPUE time series (1985-1998) available from commercial fishing fleets and bottom research surveys.

\begin{tabular}{|c|c|c|c|c|c|}
\hline Year & $\begin{array}{c}\text { Avilés } \\
\text { Bottom trawl } \\
(\mathrm{kg} / \mathrm{fday} \cdot \mathrm{BHP} / 100)\end{array}$ & $\begin{array}{c}\text { A Coruña } \\
\text { Bottom trawl } \\
(\mathrm{kg} / \mathrm{fday} \cdot \mathrm{BHP} / 100)\end{array}$ & $\begin{array}{l}\text { Portuguese } \\
\text { October survey } \\
(\mathrm{kg} / \mathrm{h})\end{array}$ & $\begin{array}{c}\text { Spanish } \\
\text { October survey } \\
\text { (kg/30 min) }\end{array}$ & $\begin{array}{l}\text { Portuguese } \\
\text { July survey } \\
(\mathrm{kg} / \mathrm{h})\end{array}$ \\
\hline 1985 & 131.22 & 118 & 3.8 & 20.93 & 9.5 \\
\hline 1986 & 116.9 & 130.84 & 23.5 & 10.14 & 4.8 \\
\hline 1987 & 109.02 & 176.65 & 6.9 & ns & $\mathrm{ns}$ \\
\hline 1988 & 88.96 & 146.63 & 26 & 12.05 & ns \\
\hline 1989 & 98.24 & 172.84 & 11.7 & 15.48 & 14.9 \\
\hline 1990 & 125.35 & 146.27 & 21.5 & 9.62 & 14.4 \\
\hline 1991 & 106.42 & 145.09 & 16.9 & 4.92 & 11.8 \\
\hline 1992 & 73.7 & 163.12 & 40.8 & 20.3 & 38 \\
\hline 1993 & 71.47 & 200.5 & 57.6 & 18.11 & 35.6 \\
\hline 1994 & 137.56 & 136.75 & 12.4 & 21.61 & 49.3 \\
\hline 1995 & 130.44 & 124.11 & 18.9 & 21.99 & 9.8 \\
\hline 1996 & 145.64 & 156.5 & 23.3 & 26.75 & $\mathrm{~ns}$ \\
\hline 1997 & 89.56 & 117.39 & 59.6 & 14.43 & 21 \\
\hline 1998 & 93.28 & $112.49^{*}$ & 15.4 & 27.99 & 14.3 \\
\hline
\end{tabular}

ns: no survey

*: CPUE estimated as the arithmetic mean of 1997 and 1999 CPUE values.

along the Atlantic shelf of northern Spain. The October surveys are coincident with the recruitment season.

The three series of surveys present great variability in abundance indices, and it is especially noticed in those carried out in the Portuguese continental shelf with changes of over $80 \%$ between consecutive years (Table 1).

The two fishing fleets are relatively stable in their characteristics over the time period. Estimates of the total annual fishing effort, $f$, were made separately from the two fishing fleets, A Coruña bottom trawl fleet and Avilés bottom trawl fleet, as follows:

$$
f_{y}=\frac{\text { Catch }_{y}}{C P U E_{j, y}}
$$

where $\mathrm{CPUE}_{j, y}$ is the CPUE of the fleet $j$ in the year $y$, and Catch $_{y}$ is the total catch of the stock in the year $y$.

There are no data of the CPUE of the A Coruña fleet for 1998. Nevertheless, data is available for 1999. Taking into account that there is no great variability in the historical data series of the A Coruña fleet, we considered it suitable to estimate CPUE for 1998 as the arithmetic mean of the values for 1997 and 1999.

Survey data were not used for the effort estimation due to the high variability observed in the time series and also because the way survey indices are currently calculated (with a stratified random sampling design) may not be the most appropriate for shoaling species such as horse mackerel.

We applied the estimation methods to each abundance index (each fishing fleet) separately to observe whether they showed different trends (Punt and Hilborn, 1996). Given that the estimates were very similar, we combined them again as the arithmetic mean of the efforts estimated from each of the fleets.

\section{The biomass-dynamic model}

The model fitted is:

$$
B_{y+1}=B_{y}+\mathrm{g}\left(B_{y}\right)-C_{y}
$$

where $\mathrm{B}_{y}$ is the biomass at the start of year $y, \mathrm{~g}(\mathrm{~B})$ is the biomass-dynamic as a function of biomass and $\mathrm{C}_{y}$ is the catch in weight during year $y$. The corresponding differential equation is:

$$
\frac{d B}{d t}=g(B)-q \cdot f \cdot B
$$

where $q$ is the catchability coefficient and $f$ is the effort ( $q \cdot f=$ fishing mortality).

In our case the biomass-dynamic function $g(B)$ is the Schaefer form (Schaefer, 1954) in which the population rate of increase is assumed to be a function of the current population size:

$$
\frac{d B}{d t}=(r-F) B-\frac{r}{K} B^{2}
$$

where $F$ is the fishing mortality. To predict catch and biomass in a short term, it is necessary firstly to establish the relationship between biomass at the start of the forecast years. Secondly, the mean annual biomass must be estimated for each year, so it is necessary to find a relationship between mean annu- 
al biomass in year $t$ and biomass at the start of that year. To obtain these two expressions we followed the re-formulation of the Schaefer (exponential) model developed in Prager (1994) and Cadima (2000):

$$
\left(B_{t+1}\right)^{-1}=r K^{-1}\left[\frac{1-e^{-\left(r-F_{t}\right) T i}}{r-F_{t}}\right]+e^{-\left(r-F_{t}\right) T i} \cdot\left(B_{t}\right)^{-1}
$$

where $B_{t+1}$, is the biomass at the start of the year $t+1$ or the biomass at the end of the year $t, B_{t}$ is the biomass at the start of the year $t$ and $T i$ is the time interval (in this study $T i=1$ year), and

$$
\bar{B}_{t}=\frac{1}{r K^{-1}} \ln \left[1-\frac{r K^{-1} B_{t}\left(1-e^{\left(r-F_{t}\right)}\right)}{r-F_{t}}\right]
$$

where $\bar{B}_{t}$ is the mean biomass in year $t$.

With this expression we can calculate catch in weight as follows:

$$
\hat{Y}_{t}=F_{t} \cdot \bar{B}_{t}
$$

Providing values to $B_{0}$ (corresponding to the biomass at the start of the time series), to $r$, to $K$, to $q$, and to $F_{0}$ (corresponding to the fishing mortality at the start of the time series), we can apply Equation (5) to obtain the biomass estimates at the start of each year. In this step we have considered $F_{t}=$ constant over the period.

Once we have obtained $B_{t}$ of each year then we can apply Equation (6) to calculate the mean biomass in each year and Equation (7) calculates the yield or total catch in each year predicted by the model. In our case we have set the yield to be equal to the actual catches, using Equation (7) to calculate $F$ in the fitting procedure (see parameter estimation section).

$F_{M S Y}, Y_{M S Y}$ and $B_{M S Y}$ have been estimated following Schaefer (1954) and Cadima (1991):

$$
\begin{gathered}
F_{M S Y}=\frac{r}{2} \\
B_{M S Y}=\frac{K}{2} \\
Y_{M S Y}=F_{M S Y} \cdot \bar{B}_{M S Y}
\end{gathered}
$$

\section{Parameter estimation}

The parameters to be estimated are $B_{0}$ and $F_{0}$ (biomass and fishing mortality at the start of the time series), $r, K$ and $q$.
We have also assumed that $F$ is proportional to the effort, $f$, in that year, which means that $F_{t}=q \cdot f_{t}$, and thus

$$
\hat{f}_{t}=\frac{F_{t}}{q}
$$

The objective function to be minimized is:

$$
\sum_{t=1}^{T}\left[\ln \left(f_{t}\right)-\ln \left(\hat{f}_{t}\right)\right]^{2}
$$

We have considered an observation-error estimation procedure, which assumes that the observed CPUE data are subject to errors. In Equation (12) we minimized the difference between the effort derived from equation (1) and that estimated by the model. It also assumes a multiplicative error structure (Prager, 1994; Punt and Hilborn, 1996).

To minimise expression (12) the "simplex" algorithm (Nelder and Mead, 1965) was applied, which is incorporated in the solver macro of Excel 97 (Microsoft software). We have allowed the $F_{t}$ to vary in each year in the fitting process, therefore the restrictions adopted to improve the minimisation process were:

* Allow only positive values.

* $Y_{t}-\hat{Y}_{t}=0$

where $\hat{Y}_{t}$ is the estimated yield by the model in the year $t$, and $Y_{t}$ is the actual catch in weight in the year $t$.

* $0.04<F_{t}<0.5$ during the first year of the time series, 1985.

* $K<1,500,000 \mathrm{t}$

* $0.0000001<q<1.0$

The initial value for $F_{0}$ was adopted from the results of the XSA assessment (ICES, 2000). For $q$ and $r$, a Schaefer production model in equilibrium conditions was run, adopting the fishing mortality from XSA. Therefore, the result was used as initial value of $q$ and $r$ for the biomass-dynamic model.

In order to find reliable parameter estimates we represented graphically the sum of squares for different $K$ and $B_{0}$ parameter combinations, selecting those values which gave a low sum of squares. In these analyses we considered the $r$ parameter as fixed and equal to 0.35 . This value is considered to be realistic, taking into account the life span of horse mackerel (more than 30 years, Eltink and Kuiter (1989)) and the values in Sullivan (1991) for redfish (0.23), a less productive species, and Northwest Atlantic mackerel (0.44), which is considered to be more productive than horse mackerel. 


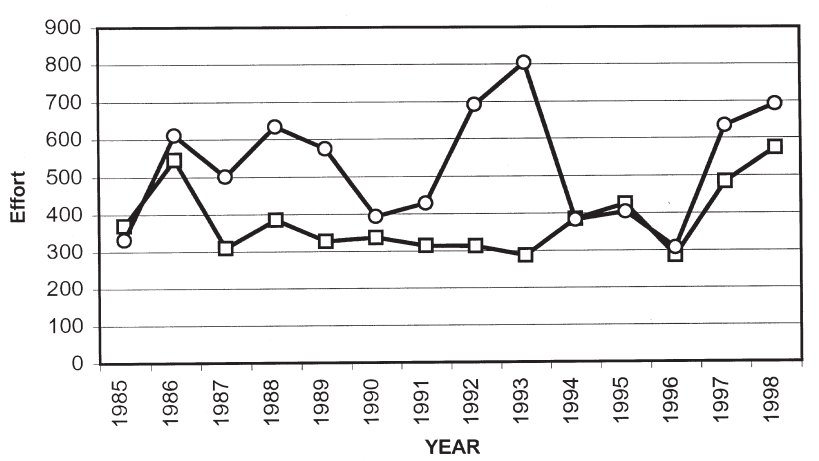

FIG. 2. - Total fishing effort (fishing day-BHP/100) series (19851998) on Southern horse mackerel estimated with Avilés bottom trawl fleet (circles) and A Coruña bottom trawl fleet (squares).

The confidence intervals for $r, q, K, B_{0}, F_{0}$ and $M S Y$ were calculated by a bootstrap procedure (Efron and Tibshirani, 1993). A total of 100 random samples were taken with replacement from the effort residuals, and each of these samples was added to the effort series, resulting in 100 bootstrap effort series replicates. The model was then fitted to each of these replicates.

\section{RESULTS}

This stock is relatively stable (Fig. 1) with catches averaging $54,055 \mathrm{t}(\mathrm{SD}=7,604 \mathrm{t})$ and peaking in 1986 and 1998. There are no remarkable trends in the two CPUE time series data (corresponding to Avilés and A Coruña fleets) used in the biomassdynamic model (Table 1), with averages of 108.4 $\mathrm{kg} /$ fishing days $\cdot \mathrm{BHP} / 100(\mathrm{SD}=23.6)$ and 146.2 $\mathrm{kg} /$ fishing days $\cdot \mathrm{BHP} / 100(\mathrm{SD}=25.7)$ respectively. BHP is the weighted mean horse power of the fishing fleet.

No clear trend can be seen from the series of effort derived from equation (1) with CPUE data from the Avilés and A Coruña bottom trawl fleets (Fig. 2). However, there has been a remarkable increase since 1996. There are no marked differences in trends between the two effort series, except in the period 1990-1994. The series obtained from Avilés bottom trawl fleet is more variable than that from A Coruña bottom trawl fleet, and presents a shift every three years since 1988, in some cases

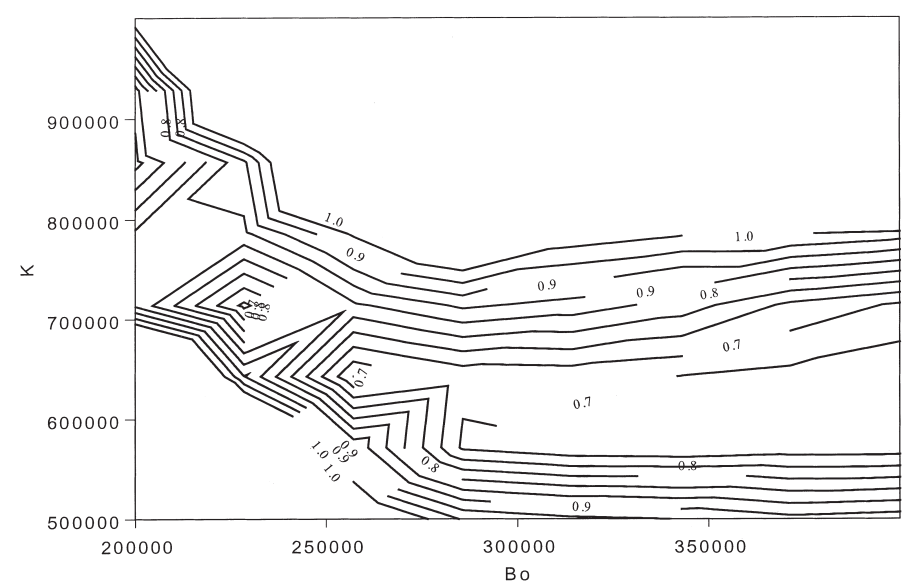

FIG. 3. - The sum of squares for different $B_{0}$ and $K$ parameter combinations. Assessment using Avilés bottom trawl fleet.

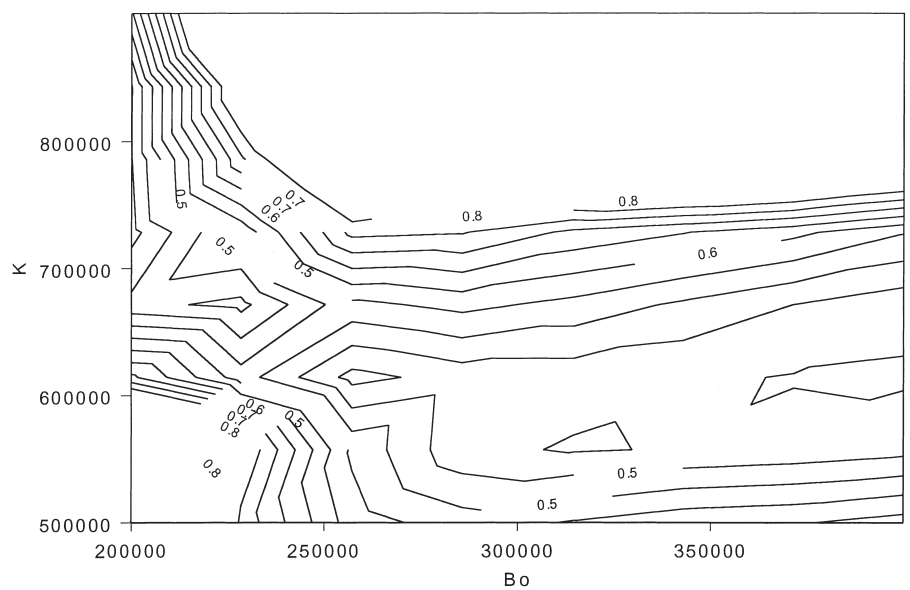

FIG. 4. - The sum of squares for different $B_{0}$ and $K$ parameter combinations. Assessment using A Coruña bottom trawl fleet. 


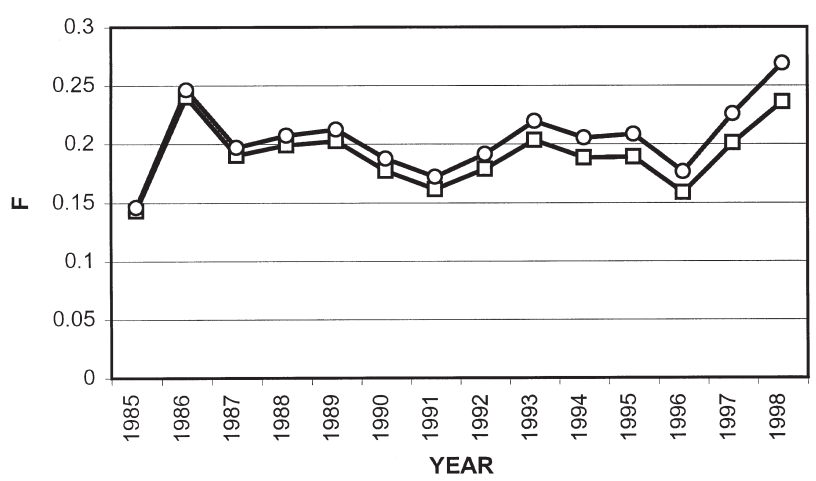

FIG. 5. - Comparison of fishing mortality estimates from assessments using Avilés bottom trawl fleet (circles) and A Coruña bottom trawl fleet (squares).

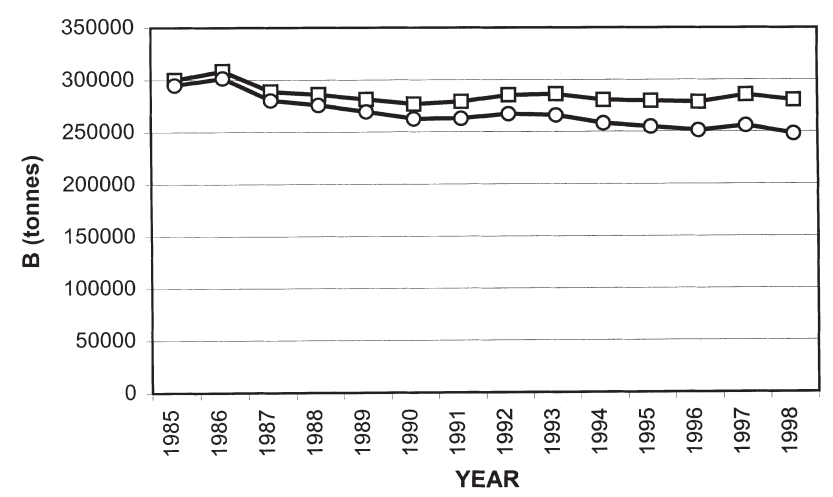

FIG. 6. - Comparison of biomass estimates (at start of the year) from assessments using Avilés bottom trawl fleet (circles) and A Coruña bottom trawl fleet (squares).

with big differences between two consecutive years (i.e. 1993-1994 and 1996-1997). The increase in effort since 1996 has implications for short-term predictions.

There is a correlation between $B_{0}$ and $K$, as can be observed in the separate assessments with each commercial fleet (Figs. 3 and 4). Therefore a wide range of parameters give equally low sum of squares in each of the assessments. The most probable values for $K$ seem to be in the range 575,000-625,000 tonnes and for $B_{0}$ between $250,000-375,000$ tonnes. A minimum was found at $B_{0} \approx K / 2, K=600,000$ tonnes.

There are no significative differences in trends of $F_{t}$ and $B_{t}$ estimates derived from the assessments with each commercial fleet (Figs. 5 and 6), assuming $B_{0}=300,000$ tonnes and $K=600,000$ tonnes.

The final assessment was carried out combining the two commercial fishing fleets. As in the previous assessments the correlation between $K$ and $B_{0}$ is also large (Fig. 7). The minimum for $K$ was estimated at 600,000 tonnes and for $B_{0}$ at 280,000 tonnes. These values were also obtained without variation during the bootstrap procedure. Results of $F_{0}, r, q, M S Y$ and $F_{M S Y}$ are given in Table 2. The standard deviations of these estimates are not very high, except for $q$, which has a coefficient of variation of $74 \%$.

The assessment shows that the current level of fishing mortality (Table 3 ) is too high if sustainability is desired. The $F$ in $1998(0.26)$ is $53 \%$ higher than the $F_{M S Y}(0.17)$ and the yield of 1998 $(64,480 \mathrm{t})$ exceeds $M S Y$ by $24 \%$. In fact, the $F$ mean over the whole time period $(0.2077)$ is also higher than the $F_{M S Y}$.

The $1998 F$ estimate from XSA (0.20, Fig. 8) exceeds slightly the fishing mortality set under the precautionary approach principle: $F_{p a}=0.18$. This estimate of $F_{p a}$ comes from the value of $F_{\max }$ estimated in the yield per recruit analysis (ICES, 1998).

Both models show an agreement in the $F$ esti-

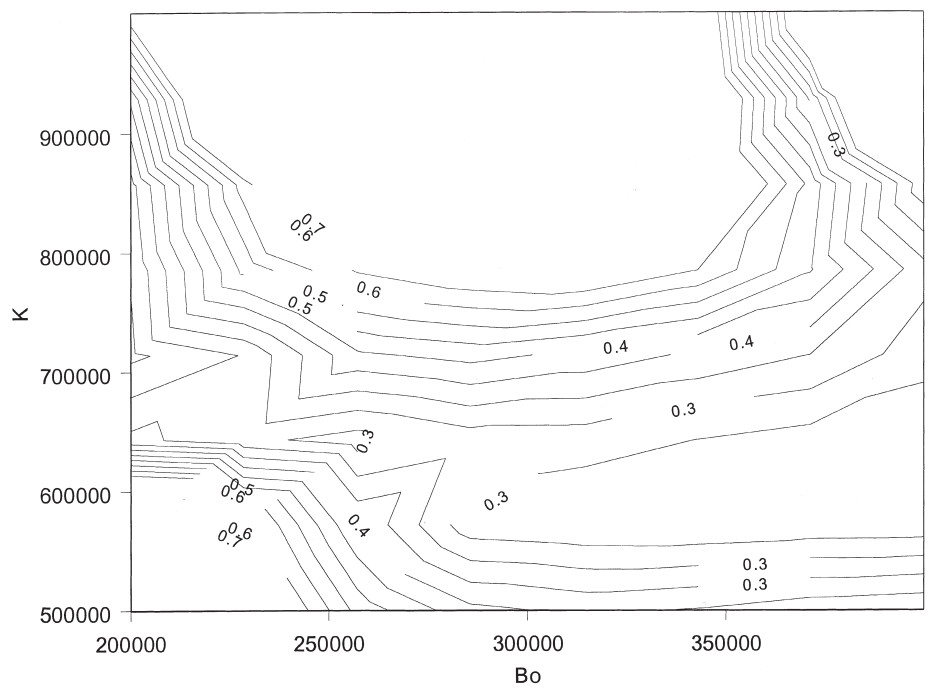

FIG. 7. - The sum of squares for different $B_{0}$ and $K$ parameter combinations. Assessment using the two commercial bottom trawl fleets (A Coruña and Avilés). 
TABLE 2. - Southern horse mackerel stock. Estimates and $95 \%$ bootstrap confidence limits of $F_{0}, q, r, F_{M S Y}$ and $M S Y$ from the biomassdynamic model ( $\mathrm{SD}=$ Standard deviation; $\mathrm{CV}=$ Coefficient of variation; $\mathrm{CL}=$ Confidence limits).

\begin{tabular}{lccccccc}
\hline & Directly estimated & Mean & Median & SD & CV\% & 95\% Lower CL & 95\% Upper CL \\
\hline$F_{0}$ & 0.1531 & 0.1529 & 0.1531 & 0.0011 & 0.71 & 0.1508 & 0.1542 \\
$q$ & 0.000463 & 0.000555 & 0.000437 & 0.000414 & 74.68 & 0.000258 & 0.001423 \\
$r$ & 0.3468 & 0.3524 & 0.3475 & 0.0269 & 7.63 & 0.3211 & 0.4037 \\
$F_{M S Y}$ & 0.1734 & 0.1762 & 0.1737 & 0.0134 & 7.63 & 0.1606 & 0.2018 \\
$M S Y$ & 52023 & 52865 & 52120 & 4035 & 7.63 & 48168 & 60548 \\
\hline
\end{tabular}

TABLE 3. - Southern horse mackerel stock. Actual catches, and estimates of biomass $\left(B_{t}\right)$ and fishing mortality $(F)$, both from biomassdynamic model, from 1985 to 1998.

\begin{tabular}{lccc}
\hline & $\begin{array}{c}B_{t} \\
\text { (tonnes) }\end{array}$ & $F$ & $\begin{array}{c}\text { Actual catches } \\
\text { (tonnes) }\end{array}$ \\
\hline 1985 & 280000 & 0.1531 & 43529 \\
1986 & 288347 & 0.2571 & 71493 \\
1987 & 268580 & 0.2047 & 54648 \\
1988 & 265321 & 0.2147 & 56392 \\
1989 & 260144 & 0.2192 & 56401 \\
1990 & 254713 & 0.1925 & 49205 \\
1991 & 256389 & 0.1756 & 45511 \\
1992 & 261938 & 0.1944 & 50956 \\
1993 & 262173 & 0.2218 & 57428 \\
1994 & 255788 & 0.2063 & 52588 \\
1995 & 254046 & 0.2082 & 52681 \\
1996 & 252114 & 0.1751 & 44690 \\
1997 & 258288 & 0.2224 & 56770 \\
1998 & 252381 & 0.2631 & 64480 \\
\hline
\end{tabular}

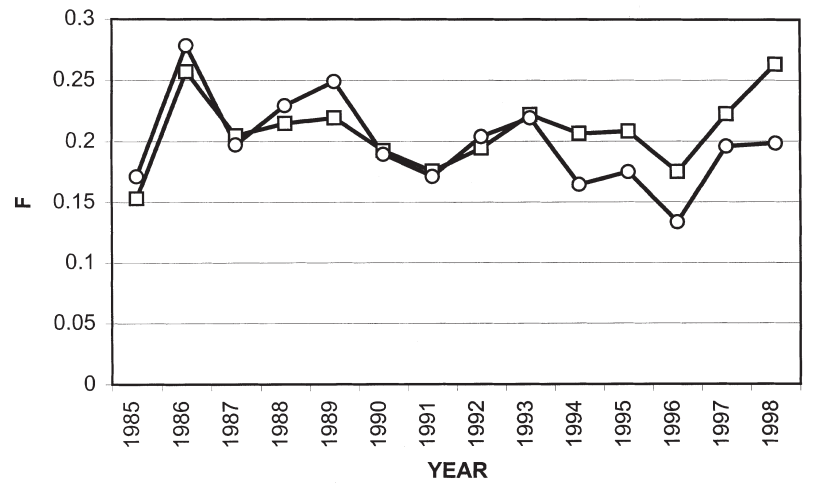

FIG. 8. - Southern horse mackerel stock. Estimates of fishing mortality (1985-1998) from XSA (circles) and biomass-dynamic model (squares).

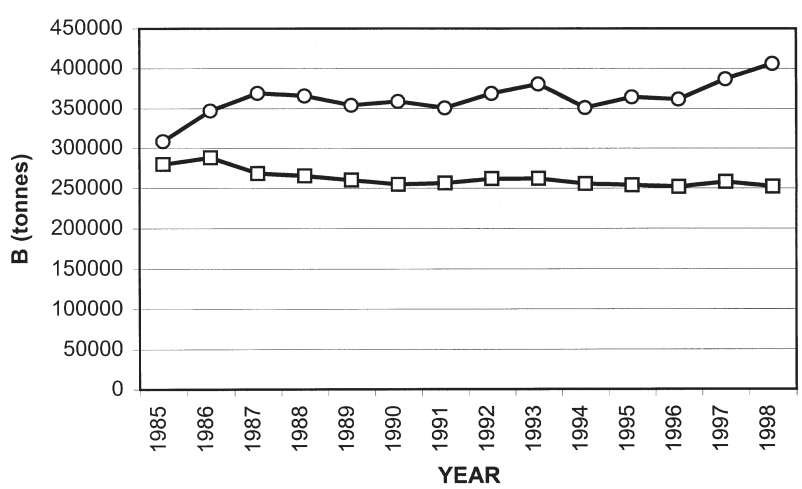

FIG. 9. - Southern horse mackerel stock. Estimates of biomass (1985-1998) from XSA (circles) and biomass-dynamic (Schaefer) (squares).
TABLE 4. - Southern horse mackerel stock. Short term prediction from XSA and biomass-dynamic model (Schaefer) under $F_{s q}$ conditions $\left[F_{s q}\right.$ : average $\left.F(1996-1998)\right]$.

\begin{tabular}{lllll}
\hline & \multicolumn{2}{c}{$\begin{array}{c}\text { Biomass (at start of the year) } \\
\text { (tonnes) }\end{array}$} & \multicolumn{2}{c}{$\begin{array}{c}\text { Yield } \\
\text { (tonnes) }\end{array}$} \\
& XSA & Schaefer & XSA & Schaefer \\
\hline 1999 & 389263 & 247895 & 60723 & 54155 \\
2000 & 378865 & 244072 & 60954 & 53375 \\
2001 & 369982 & 240801 & 59875 & 52707 \\
\hline
\end{tabular}

TABLE 5. - Southern horse mackerel stock. Short term prediction from XSA and biomass-dynamic model (Schaefer), under $F_{M S Y}$ conditions for Schaefer model and $F_{\text {max }}$ conditions for XSA.

\begin{tabular}{ccccc}
\hline & \multicolumn{3}{c}{$\begin{array}{c}\text { Biomass (at start of the year) } \\
\text { (tonnes) }\end{array}$} & \multicolumn{2}{c}{$\begin{array}{c}\text { Yield } \\
\text { (tonnes) }\end{array}$} \\
& XSA & Schaefer & XSA & Schaefer \\
\hline 1999 & 389263 & 258924 & 65088 & 45411 \\
2000 & 373952 & 264694 & 64444 & 46348 \\
2001 & 360890 & 269748 & 62615 & 47167 \\
\hline
\end{tabular}

mates (Fig. 8), with the same trends over the time period. Still, some discrepancies in the level of $F$ between years exist, in particular since 1994 onwards.

The estimates of biomass given by the biomassdynamic model remains approximately at the same level over the whole period, whereas the XSA estimates are more optimistic, showing increasing biomass in recent years (Fig. 9). The mean difference between the biomass estimates from the two models is about $100,000 \mathrm{t}$.

Considering the status quo basis for predictions as the mean of $F$ estimates from 1996 to 1998, results from XSA are more optimistic although the biomass has a decreasing trend through the prediction period (Table 4).

Under $F_{M S Y}$ assumptions, the biomass increases through the prediction period and the yield is around $46,000 \mathrm{t}$ (Table 5). This seems the most advisable level for the sustainability of the stock. 
$F_{\max }$, estimated from the yield per recruit analysis, with input data from XSA, is the reference point for $F_{p a}$ for this stock. However, at this level of $F$ the biomass decreases through the short-term prediction period with a yield between 65,000 and $62,000 \mathrm{t}$ (Table 5).

\section{DISCUSSION}

Southern horse mackerel is usually fished by bottom trawlers and purse seiners. The high catches of horse mackerel in 1998 are due to increased purse seining on this species as an alternative to sardine (ICES, 2000). One of the main difficulties in fishery assessment models is the assumption of a constant catchability (Hilborn and Walters, 1992; Lleonart, 1993). We consider CPUE series from bottom trawl fleets fulfill this assumption better than that of the purse seiners. Avilés and A Coruña bottom trawl fleets have not shown major changes during the time series. Also the CPUE-at-age series are, in the XSA assessment, in good agreement with the estimated abundance for adult ages ( $>3$ years old) (ICES, 2000). All these reasons support the use of the Avilés and A Coruña trawl fleets data for the total effort estimation in biomass-dynamic model.

Hilborn (1979) described some possible problems in the parameter estimation of biomass-dynamic models: i) insufficient contrasts in the effort or CPUE series; ii) the series analysed begins after a period of intensive fishing and iii) difficulties in obtaining reasonable parameter estimates with longlived species. Despite the fact that Southern horse mackerel stock presents some of these problems, the biomass-dynamic model produces reasonable parameter estimates. This may be due to the relative stability both in stock abundance and effort, giving a quasi-equilibrium state during the assessment period. Previous results of biomass and fishing mortality from the XSA assessment, facilitate the selection of initial values and restrictions for the parameters when fitting the biomass-dynamic model.

Observation-error estimators are, in the majority of cases, the least biased and the most precise (Polachek et al., 1993; Punt and Hilborn, 1996). In our case we have minimised the differences between the natural logarithms of observed and estimated effort. Log transformation had the effect of stabilizing the variance and approximates to normal distribution (Punt and Hilborn, 1996). The reliability of the values obtained for $M S Y$ and $F_{M S Y}$ as well as for $r$ is suggested by the narrow bootstrap confidence intervals, lack of bias in the bootstrap estimates, and by the agreement with the XSA assessment. Taking into account that the Southern horse mackerel is an old fishery, exploited commercially since the beginning of the 20th century, it seems to be reasonable to have a level of $B_{0}$ a bit lower or close to $K / 2$. Furthermore, the value of parameter $r$ lies in the expected range for a relatively long-lived species (Sullivan, 1991). The confidence limits of $q$ are very wide, being a consequence of the difficulties in obtaining precise parameter estimates when there is no contrast in the data available.

The biomass-dynamic and age-structured models provided similar results regarding the state of the stock. Both state that the current level of fishing mortality is high under the precautionary criteria and that historically, $F$ has been very close to the overexploitation of the stock. The probability that the assessment is an accurate reflection of the stock, increases if the two models give the same figure (Hilborn and Walters, 1992), as is the case. However, the XSA model gives higher biomass estimates, especially for the last year of the series. The XSA model incorporates fishery independent information (bottom trawl surveys) in the assessment whereas biomass-dynamic model does not. This difference could be in part responsible for the different perception of the biomass estimates, taking into consideration that the Portuguese October survey gives a signal of very high population abundance (see ICES, 2001). On the other hand, in the biomass-dynamic model, there are also uncertainties associated with the estimation of $B_{0}$, giving a wide range of possible values. Usually, biomass-dynamic models tend to estimate better the biomass level of the last years whereas the VPA-based methods give better estimates of initial biomass (Prager, 1994). One of the major inconveniences of the VPA-based methods is that the final parameter estimates depend critically on the choice of terminal F, even when the "tuned" models are applied (Freón and Misund, 1999). In XSA, the estimates of catchability for the oldest age are directly dependent on the terminal population used to initialise the underlying VPA, which does the calculations backward in time from some known endpoint (Hilborn and Walters, 1992; Darby and Flatman, 1994). This means that XSA is expected to give more imprecise abundance estimates on recent years than at the start of the assessment period. The recruitment in recent years is very difficult to estimate with precision. In the Southern horse mackerel 
the recruitment in 1998 was estimated as the geometric mean of the time series 1985-1996 (ICES, 2000). Given the decreasing trend in recruitment in the latest years, the geometric mean could overestimate the recruitment in 1998. The retrospective analysis of the Southern horse mackerel stock (ICES, 2001) shows that the XSA assessments overestimate systematically the biomass level in the last year's assessment. All these factors can help to explain the differences in biomass trend in recent years between the two models. Other source of uncertainty in biomass-dynamic models is related to the integration into a single function (of stock size) the effect of tissue growth, natural mortality and reproduction (Punt and Hilborn, 1996). Like in any non-linear estimation procedure the estimation of parameters is sensitive to the initial values. This is the case of $B_{0}$ and $K$, which are related to the stock conditions at the start of the assessment period. The estimate of $B_{0}$ is imprecise, unless auxiliary information be available (Prager, 1994). In the Southern horse mackerel the amount of correlation found between the parameters $K$ and $B_{0}$ confirms this difficulty in obtaining precise parameter estimates.

Management with $M S Y$ as reference point has been replaced by other control actions in which the yield is the most satisfactory combination of as many factors as are necessary to the sustainability of the fishery (Pitcher and Hart, 1982). Indeed management based on effort controlled models is less risky than with the use of catch-controlled ones (Caddy and Mahon, 1995; Kizner, 1997). However, $M S Y$ and $F_{M S Y}$ still are useful, especially when all information available on the state of the stock is taken into account (Pitcher and Hart, 1982; Prager, 1994).

In the Southern horse mackerel stock, $M S Y$ and $F_{M S Y}$ management objectives seem to be conservative and precautionary, and look therefore suitable for assuring recruitment (ICES, 1998). In the predictions made the only management action that produces an increasing biomass is the $F_{M S Y}$ regime. It seems that the $F_{p a}$ established under the XSA model, which is equal to $F_{\max }$ (ICES, 1998), is at present conditions a fishing mortality level too high to avoid a decrease in biomass throughout the prediction period. In principle, $F_{\max }$ is not a good candidate for a precautionary reference point, considering the uncertainties associated to the yield-per-recruit analysis: assumption of equilibrium conditions in the fishery and no density dependent effects on stock dynamics.
In this paper we have made a first attempt to compare a biomass-dynamic model with a VPAbased method for Southern horse mackerel stock, following the interest in such comparisons showed by Schaefer and Beverton (1963) and Hilborn and Walters (1992). Further analysis with biomassdynamic models must be done, such as including in the assessment other appropriate fishery independent information. Nevertheless, we can conclude that biomass-dynamic models can be applied successfully to the Southern horse mackerel stock and can give useful complementary information to the age-structured models, both in the perception of the state of the stock and in the definition of management targets.

\section{ACKNOWLEDGEMENTS}

Authors 1 and 3 wish to thank E. Cadima and M. Azevedo for their helpful training course on production models. Thanks also to two anonymous referees and to $\varnothing$. Ulltang for their valuable comments. This work has been carried out under the project BIOJUVER funded by the Instituto Español de Oceanografía. Contribution of the $3^{\text {rd }}$ author was done within IPIMAR programme "Pelágicos".

\section{REFERENCES}

Cadima, E.L. - 1991. Some relationships among biological reference points in general production models. ICCAT, Coll. Vol. Sc. Papers, Vol. XXXIX: 27-30.

Cadima, E.L. - 2000. Manual de avaliaçao de recursos pesqueiros. FAO Documento Técnico sobre as Pescas, No. 393, Roma, $262 \mathrm{pp}$.

Caddy, J.F. and R. Mahon. - 1995. Reference points for fisheries management. FAO Fish. Techn. Paper., 347. Rome, FAO.

Darby, C.D. and S. Flatman. - 1994. Virtual population analysis: version 3.1 (Windows/DOS) user guide. MAFF Directorate of Fisheries Research IT Report 1.

Efron, B. and R.J. Tibshirani. - 1993. An introduction to the bootstrap. Chapman \& Hall, London.

Eltink, A. and C.J. Kuiter. - 1989. Validation of ageing techniques on otolith of horse mackerel (Trachurus trachurus, L.). ICES C.M. 1989/H: 43.

Fréon, P. and O.A. Misund. - 1999. Dynamics of Pelagic Fish Distribution and Behaviour: Effects on Fisheries and Stock Assessment. Fishing New Books, Cambridge.

Getz, W.M. and R.G. Haight. - 1989. Population Harvesting. Demographic Models of Fish, Forest, and Animal Resources. Princeton University Press, Princeton, New Jersey.

Hilborn, R. - 1979. Comparison of fisheries control systems that utilize catch and effort data. J. Fish. Res. Bd. Can., 36: 14771489.

Hilborn, R. and C.J. Walters. - 1992. Quantitative fisheries stock assessment. Choice, dynamics \& uncertainty. Chapman and Hall, New York.

ICES. - 1998. Report of the Study Group on Precautionary Approach to Fishery Management. ICES C.M. 1998/ACFM: 10.

ICES. - 1999a. Report of the Study Group on Multiannual Assessment Procedures. ICES C.M. 1999/ACFM: 11. 
ICES. - 1999b.- Reports of Working Groups on Methods of Fish Stock Assessment (Meetings in 1993 and 1995). ICES Coop. Res. Rep., 230.

ICES. - 2000. Report of the Working Group on the Assessment of Mackerel, Horse Mackerel, Sardine and Anchovy. ICES C.M. 2000/ACFM: 5

ICES. - 2001. Report of the Working Group on the Assessment of Mackerel, Horse Mackerel, Sardine and Anchovy. ICES C.M. 2001/ACFM: 06.

Kizner, Z. - 1997. Stability properties of discrete stock-production models. Sci. Mar., 61(2): 195-201.

Laloë, F. - 1995. Should surplus production models be fishery description tools rather than biological models?. Aquat. Living Resour., 8: 1-16.

Lleonart, J. - 1993. Methods to analyse the dynamics of exploited marine populations: Use and development of models. Sci. Mar., 57(2-3): 261-267.

Ludwig, D. and C.J. Walters. - 1985. Are age-structured models appropriate for catch-effort data?. Can. J. Fish. Aquat. Sci., 42: 1066-1072.

Nelder, J.A. and R. Mead. - 1965. A simplex method for function minimization. Computer Journal, 7: 308-313.

Patterson, K.R. and G.P. Kirkwood. - 1995. Comparative performance of ADAPT and Laurec-Shepherd methods for estimating fish population parameters and in stock management. ICES J. Mar. Sci., 52: 183-196.

Pérez, N., V. Trujillo and P. Pereda. - 1999. Landings and discards of the trawl fleets of Spanish ICES Divisions VIIIc and IXa in
1997. In: On-board sampling of fish landed and discarded by commercial vessels. Final Report EC Project: 95/094.

Pitcher, T.J. and P.J. Hart. - 1982. Fisheries Ecology. Chapman \& Hall, London.

Polacheck, T., R. Hilborn and A.E. Punt. - 1993. Fitting surplus production models: comparing methods and measuring uncertainty. Can. J. Fish Aquat. Sci., 50: 2597-2607.

Pope, J.G. - 1972. An investigation of the accuracy of virtual population analysis using cohort analysis. ICNAF Res. Bull., 9: 65-74.

Prager, M.H. - 1994. A suite of extensions to a nonequilibrium surplus-production model. Fish. Bull., 92: 374-389.

Punt, A.E. - 1995. The performance of a production-model management procedure. Fish. Res., 21: 349-374.

Punt, A.E. and R. Hilborn. - 1996. Biomass dynamic models. FAO Computerized Information Series (Fisheries), 10.

Quinn, T.J. II, R.B. Deriso and S.H. Hoag. - 1985. Methods of population assessment of Pacific halibut. IPHC Scientific Report, 72.

Schaefer, M. B. - 1954. Some aspects of the dynamics of populations important to the management of the commercial marine fisheries. Bull. Inter-Am. Trop. Tuna Comm., 1(2): 27-56.

Schaefer, M.B. and R.J.H. Beverton. - 1963. Fishery dynamics: their analysis and interpretation. In: M.N. Hill (ed.), The Sea. Vol. 2, pp: 464-483. John Wiley and Sons, New York.

Shepherd, J.G. - 1999. Extended survivors analysis: An improved method for the analysis of catch-at-age data and abundance indices. ICES J. Mar. Sci., 56: 584-591.

Sullivan, K.J. - 1991. The estimation of parameters of the multispecies production model. ICES mar. Sci. Symp., 193: 185-194. 